\title{
IMAGENS EM LIQUIDAÇÃO
}

\author{
Mateus Gonçalves de Medeiros
}

\author{
RESUMO
}

Este trabalho tem como objetivo debater a concepção de cinema segundo Walter Benjamin, para quem o cinema é uma reviravolta dos paradigmas estéticos adotados e regulamentados pela história da arte tradicional e não mais produto de um engenho individual. O cinema se trata de uma produção coletiva que questiona a perda da individualidade da própria obra de arte em geral que se torna passível de reprodução em massa. É possível afirmar que essa questão significa o surgimento de um modelo de obra de arte que vai além de uma mera reprodução do original: no filme não há sequer um original, mas apenas cópias. Com base nessas questões o autor repensa valores da História da Arte a ponto de investigar o que ele denomina "liquidação do patrimônio tradicional da cultura”. É importante observar que a destruição da aura da obra de arte já iniciada anteriormente com as vanguardas do século XIX se completa naturalmente com o advento da obra de arte que não possui original. Para além da questão artística, esse evento significa pôr em cheque valores antiquíssimos. O valor de eternidade, por exemplo, é questionado no âmbito cultural, o que conduziria a uma valorização do efêmero e do transitório influenciando não apenas a Estética e as Teorias da Arte, mas o mundo civil como um todo.

Palavras-Chaves: Cinema. Coletividade. Walter Benjamin. Individualidade

\section{IMAGES ON SALE}

\begin{abstract}
This work aims to discuss the conception of cinema according to Walter Benjamin for whom the cinema is a twist of aesthetic paradigms adopted and regulated by the traditional history of art and no longer a product of an individual creation. The cinema is a collective production that questions the loss of the individuality of art, which could become potentially a reproduction. It is possible to say that this means the emergence of a model which goes beyond the original copy of the original: in the film, there is no original, only copies. Based on these questions the author rethinks the history of art investigating what he calls the "liquidation of the traditional heritage of culture". It is important to note that the destruction of the aura of the work of art already begun earlier with the avant-garde of the nineteenth century, which is naturally completed with the advent of the Cinema,
\end{abstract}


a work of art that has no original. Beyond the artistic question, this event means to put on hold traditional values such as the value of eternity or the value of authority. The ideas eternalized are questioned in the cultural sphere while an appreciation of the ephemeral and transient begins, which influences not only the aesthetics and the theory of art, but the civil society as a whole.

Keywords: Film. Collectivity. Walter Benjamin. Individuality

"O filme é uma criação da coletividade"1. A afirmação de Walter Benjamin indica a relação indispensável entre as massas e a produção cinematográfica. Diferente da pintura, que era produzida para o desfrute de um único indivíduo ou, no máximo, um público pequeno amontoado à frente de um quadro, o filme é uma obra voltada para a fruição coletiva. Não se trata de uma opção criativa, mas de uma necessidade. Os custos extremamente elevados para a sua produção, especialmente nos tempos que antecedem o advento do vídeo e, posteriormente, da digitalização, obrigavam a produção cinematográfica a depender de uma grande massa de espectadores para cobrir os custos e ainda oferecer lucro aos produtores. Essa questão evidencia a forte ligação que se estabelece no cinema entre obra e público. O filme precisa voltar-se para um grande número de espectadores, ao contrário de um quadro, que pode ser financiado com poucos recursos, mesmo sem clientes em potencial. Essa condição, apesar de cada vez mais suavizada pela tecnologia digital, se manifesta fortemente ainda hoje nas grandes produções cinematográficas de massa, que preestabelecem no projeto de sua produção um número mínimo de

\footnotetext{
1 No trecho completo, afirma Benjamin: "Nas obras cinematográficas, a reprodutibilidade técnica do produto não é, como no caso da literatura ou da pintura, uma condição externa para sua difusão maciça. A reprodutibilidade técnica do filme tem seu fundamento imediato na técnica de sua produção. Esta não apenas permite, da forma mais imediata, a difusão em massa da obra cinematográfica, como a torna obrigatória. A difusão se torna obrigatória, porque a produção de um filme é tão cara que um consumidor, que poderia, por exemplo, pagar um quadro, não pode mais pagar um filme. O filme é uma criação da coletividade. Em 1927, calculou-se que um filme de longa-metragem, para ser rentável, precisaria atingir um público de nove milhões de pessoas". BENJAMIN, Walter. A Obra de Arte na Época de sua Reprodutibilidade Técnica. In: Magia, Técnica, Arte e Política: ensaios sobre literatura e história da cultura. Obras Escolhidas. Volume I. Trad. br. Sergio Paulo Rouanet. São Paulo: Brasiliense, 1985, 172.
}

Mestre em Filosofia pela Universidade Estadual do Ceará. Brasileiro, residente em FortalezaCE. Email: mateusgoncalves@gmail.com 
espectadores a ser atingido para que o filme possa ser considerado bemsucedido como empreendimento mercadológico.

É mais comum entendermos a fruição em massa do cinema no sentido clássico da crítica ao produto cultural massificado: o filme de massa, no desespero de se sustentar, reiteraria clichês cada dia mais esgotados e os apresenta a um público que é compreendido como uma massa disforme e homogênea. Reduzidas a um mínimo denominador comum, as individualidades que formam um público são ignoradas pelo filme que apresenta uma produção artística estandardizada onde o imediato objetivo é a capitalização de um produto cultural. Sem se importar com as possíveis consequências funestas dessa atitude, o filme de massa termina por contribuir para o embotamento das singularidades do indivíduo e, na visão frankfurtiana, ao desestímulo à sua consciência de classe. Essa análise foi elaborada por Theodor Adorno e Max Horkheimer que, em sua reflexão sobre o advento da indústria cultural, apresenta a perversão do mercado cinematográfico. Entretanto, sem necessariamente negar a argumentação de Adorno e Horkheimer, Walter Benjamin vislumbra a possibilidade de compreender o público sob uma postura menos passiva. Afinal, trata-se do advento de uma produção artística onde os espectadores reunidos em uma sala de projeção coletiva possuiriam em potência um poder despercebido de controle sobre a produção artística. Isso ocorre devido a necessidade de que o público esteja presente e participante para uma grande produção cinematográfica ser possível ${ }^{2}$. O controle em potência que a massa possui em mãos atingiria mesmo a interpretação do ator, antes sequer do público do filme efetivamente existir. Afirma Walter Benjamin sobre 0 ator cinematográfico:

Ele sabe, quando está diante da câmara, que sua relação é em última instância com a massa. É ela que vai controlá-lo. E ela, precisamente,

\footnotetext{
2 Para além da simples constatação do poder em potência do público de cinema, Benjamin parece se perguntar sobre as possibilidades da mobilização desse agrupamento político que ali se instaura. Dessa forma, seria possível que esse poder seja catalisado em prol das massas e, consequentemente, em favor da transformação social, política e econômica da sociedade? Essa questão está presente na medida em que Benjamin comenta a capacidade das massas de uma sessão de cinema de se autorregularem naturalmente em grupo. Entretanto, apesar de citar essa autorregulação, Benjamin não deixa claro como mobilizar as massas para que elas despertem para a consciência desse poder.
}

Mestre em Filosofia pela Universidade Estadual do Ceará. Brasileiro, residente em Fortaleza-

CE. Email: mateusgoncalves@gmail.com 
não está visível, não existe ainda, enquanto o ator executa a atividade que será por ela controlada. Mas a autoridade desse controle é reforçada por tal invisibilidade. (BENJAMIN, 1985)

O argumento de que a massa impõe controle sobre 0 ator, mesmo antes de sua existência, nos conduz à leitura de uma massa não mais tão impotente ou passiva quanto de costume nas discussões sobre as indústrias da cultura. $O$ poder está com o público porque é para ele que o filme é produzido. Da mesma maneira, é para chegar até ele que o ator representa para a câmera. Seu objetivo é o de satisfazer o público que o assistirá, de o encantar com o seu desempenho, de se comunicar diretamente com ele. No cinema, o bobo atua prioritariamente para o grande público, não para o rei. Entretanto, para que se possa aproveitar o potencial político desse controle, seria preciso que o cinema se libertasse da exploração que sofre pelas intenções capitalistas inerentes à sua indústria. Afirma Benjamin:

Não se deve, evidentemente, esquecer que a utilização política desse controle terá que esperar até que o cinema se liberte da sua exploração pelo capitalismo. Pois o capital cinematográfico dá um caráter contrarrevolucionário às oportunidades revolucionárias imanentes a esse controle. Esse capital estimula o culto do estrelato, que não visa conservar apenas a magia da personalidade, há muito reduzida ao clarão putrefato que emana do seu caráter de mercadoria, mas também, seu complemento, o culto do público, e estimula, além disso, a consciência corrupta das massas, que o fascismo tenta pôr no lugar de sua consciência de classe.(BENJAMIN, 1985, 180)

O cinema que permanece sob o poder do capital não pode liberar suas energias para o despertar político. A submissão da produção cinematográfica aos interesses da indústria impede seu potencial revolucionário. $O$ estímulo ao culto das personalidades tem como objetivo se beneficiar economicamente da aura fabricada das celebridades, insistindo no aumento de seu valor de culto, no mesmo proceder do consumo excitado pela fetichização da mercadoria.

Apesar do alerta de Benjamin para o fato de que o caráter revolucionário do cinema somente poderá ser utilizado após a libertação das amarras do capitalismo, surge no texto uma possibilidade de emancipação mesmo no interior do cinema capitalista. Segundo Walter Benjamin, as possibilidades progressistas 
do cinema podem se manifestar mesmo em filmes burlescos (grotesken), como os de Chaplin, que, pode-se dizer, constituíram grandes produções fortemente capitalizadas em seu contexto histórico. Segundo ele, "a reprodutibilidade técnica da obra de arte modifica a relação da massa com a arte. Retrógrada diante de Picasso, ela se torna progressista diante de Chaplin" (BENJAMIN, 1985, 187). O comportamento progressista a que Benjamin se refere é a capacidade de o público poder desfrutar de um filme ao mesmo tempo em que se constrói uma atitude crítica no coração dos espectadores. Uma cena de Tempos Modernos não deixa de ser ao mesmo tempo divertida, pelo seu caráter caricato, e crítica, pela poderosa imagem do ser humano que se transforma em instrumento mecânico.

Ao riso fácil da comédia slapstick se acrescenta sob uma mais profunda camada de significado um conteúdo de criticidade que o espectador experimenta, às vezes, de maneira despercebida. Uma reflexão crítica que não é fruto de uma contemplação detida sobre uma cena, uma vez que a dinâmica dos cortes da narrativa cinematográfica não permitiria o descanso dos olhos em uma imagem paralisada, condição sine qua non para se efetivar a atenção e o recolhimento necessários à contemplação. O que é possível na fruição de uma cena pintada em um quadro difere qualitativamente de uma sequência exibida em uma tela de projeção. A primeira oferece tempo para a reflexão. A segunda ocupa esse tempo.

Compare-se a tela em que se projeta o filme com a tela em que se encontra o quadro. Na primeira a imagem se move, mas na segunda, não. Esta convida o espectador à contemplação; diante dela, ele pode abandonar-se às suas associações. Diante do filme, isso não é mais possível. Mal o espectador percebe uma imagem, ela não é mais a mesma. Ela não pode ser fixada, nem como um quadro nem como algo de real. (BENJAMIN, 1985, 187)

Eis a diferença que Benjamin identifica como uma ruptura inédita no modo de percepção da obra de arte. Desde a constituição dos paradigmas da arte ocidental na antiguidade greco-romana, a fruição estética se deu no âmbito do recolhimento. Pela primeira vez na história a fruição se movimenta em direção à uma atividade distraída, na medida em que não é esperado deter-se defronte de uma sequência fílmica e deixar-se levar rumo a uma livre associação de ideias. 
A fruição como atividade distraída é um conceito ambivalente. Na esteira de um pensamento de orientação frankfurtiana, uma atividade de fruição distraída em detrimento de uma fruição com base no recolhimento seria possivelmente vislumbrada na chave da alienação do fruidor. Este, incapaz de recolher-se para se aprofundar na contemplação, estaria relegado a uma postura superficial do ponto de vista do desenvolvimento de um pensamento crítico e de uma análise demorada da imagem por ele percebida. Isso o conduziria fatalmente à impossibilidade de articular uma reflexão crítica, o colocando à disposição como mais uma peça idêntica do conjunto homogêneo da massa de manobra.

Entretanto, a superficialidade da fruição distraída pode revelar resultados surpreendentes. No momento em que seu consciente se encontra paralisado diante das imagens que o golpeiam, sua percepção está desperta e adquirindo as imagens. Os significados formulados podem permanecer inertes, temperando lentamente, enriquecendo-se de sabores e aromas, esperando o momento para emergir após a sessão. A visão de Chaplin vestido como um operário, que se mecaniza por meio da repetição dos movimentos, gera momentos de prazer e deleite pela sua comicidade. Entretanto, a imagem pode ir além, possuindo a capacidade de retornar paralisada pelo pensamento e interpretada sob um ponto de vista crítico. O absurdo que gera o cômico transforma-se no verossímil que estimula a crítica.

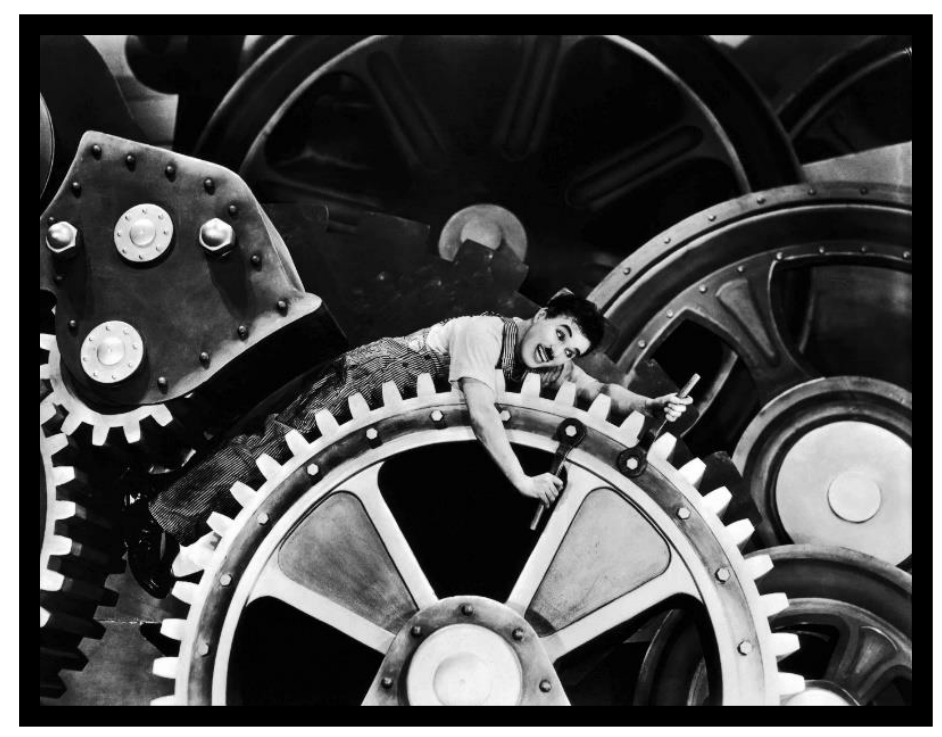

Mestre em Filosofia pela Universidade Estadual do Ceará. Brasileiro, residente em FortalezaCE. Email: mateusgoncalves@gmail.com 
O conteúdo crítico inerente à imagem de um homem que mecaniza seus gestos por consequência da repetição e que se torna, figurativa e literalmente, engrenagem de máquina ao ser carregado pelas rodas dentadas gigantes do maquinário, é uma imagem que comunica distraidamente a condição alienante do operário. Em O Ditador, Chaplin é lembrado por outra célebre sequência: um chefe de estado de nome Adenoid Hinkel se diverte com a miniatura de um globo terrestre. Seus gestos são assemelhados aos de uma criança que brinca inconsciente de sua irresponsabilidade. Em uma primeira leitura, o espectador ri do gestual circense e bufão. Entretanto, a força simbólica e sintética da imagem pode revelar um aprendizado que, passado um tempo de maturação, poderia surgir sob a forma de uma compreensão política antifascista ${ }^{3}$. Dessa forma, pode-se compreender a afirmação de Benjamin de que "a reprodutibilidade técnica da obra de arte modifica a relação da massa com a arte. Retrógrada diante de Picasso, ela se torna progressista diante de Chaplin". Por meio da distraída fruição de um filme de Chaplin, surge um movimento que conduziria ao esclarecimento, consistindo, nos dizeres de Otília Arantes, em uma distração "esclarecida"4.

\footnotetext{
${ }^{3}$ Arriscando uma interpretação que dialogue com os textos de Benjamin que se remetem a suas reflexões gnosiológicas, tratar-se-ia de uma imagem que transmite um conteúdo de verdade que estimula uma relação não do plano da informação ou do saber, mas da ordem de uma experiência, de um experienciar um teor de verdade em que o agora da cognoscibilidade de uma imagem se paralisa no pensamento. Ver BENJAMIN, Walter. Origem do Drama Barroco Alemão. Trad. br. Sergio Paulo Rouanet. São Paulo: Brasiliense, 1984, e BENJAMIN, Walter. Escritos sobre mito e linguagem. Trad. br. Susana Kampff Lages e Ernani Chaves. São Paulo: Editora 34, 2011.

${ }^{4}$ Sobre a distração esclarecida de Benjamin, cito um trecho de Otília Arantes: "Não é difícil reconhecer a lição de Brecht nesse raciocínio ["o da distração esclarecida"] que, invertendo o negativo em positivo, transforma a "distração" em ponto de vista interessado, e vice-versa, a atenção suprema da consciência estética, em entorpecimento, como o transe do wagneriano hipnotizado. Para Adorno, a teoria benjaminiana da distração "esclarecida" pecava por espontaneísmo: transformar as massas populares em sujeito coletivo do cinema, por exemplo, é esquecer perigosamente o quanto elas são portadoras de todos os traços da mutilação da personalidade característica do progresso capitalista. Certamente Benjamin sabia muito bem que o riso dos frequentadores de cinema poderia não ser cordial e muito menos revolucionário, mas acreditava que a recepção coletiva reproduzida pelo aparato técnico emergente poderia liberar o potencial cognitivo até então aprisionado nos domínios confinados da cultura afirmativa. Em resumo: que a distração estética do especialista amador, a um tempo atenção flutuante e Mestre em Filosofia pela Universidade Estadual do Ceará. Brasileiro, residente em Fortaleza-
}

CE. Email: mateusgoncalves@gmail.com 


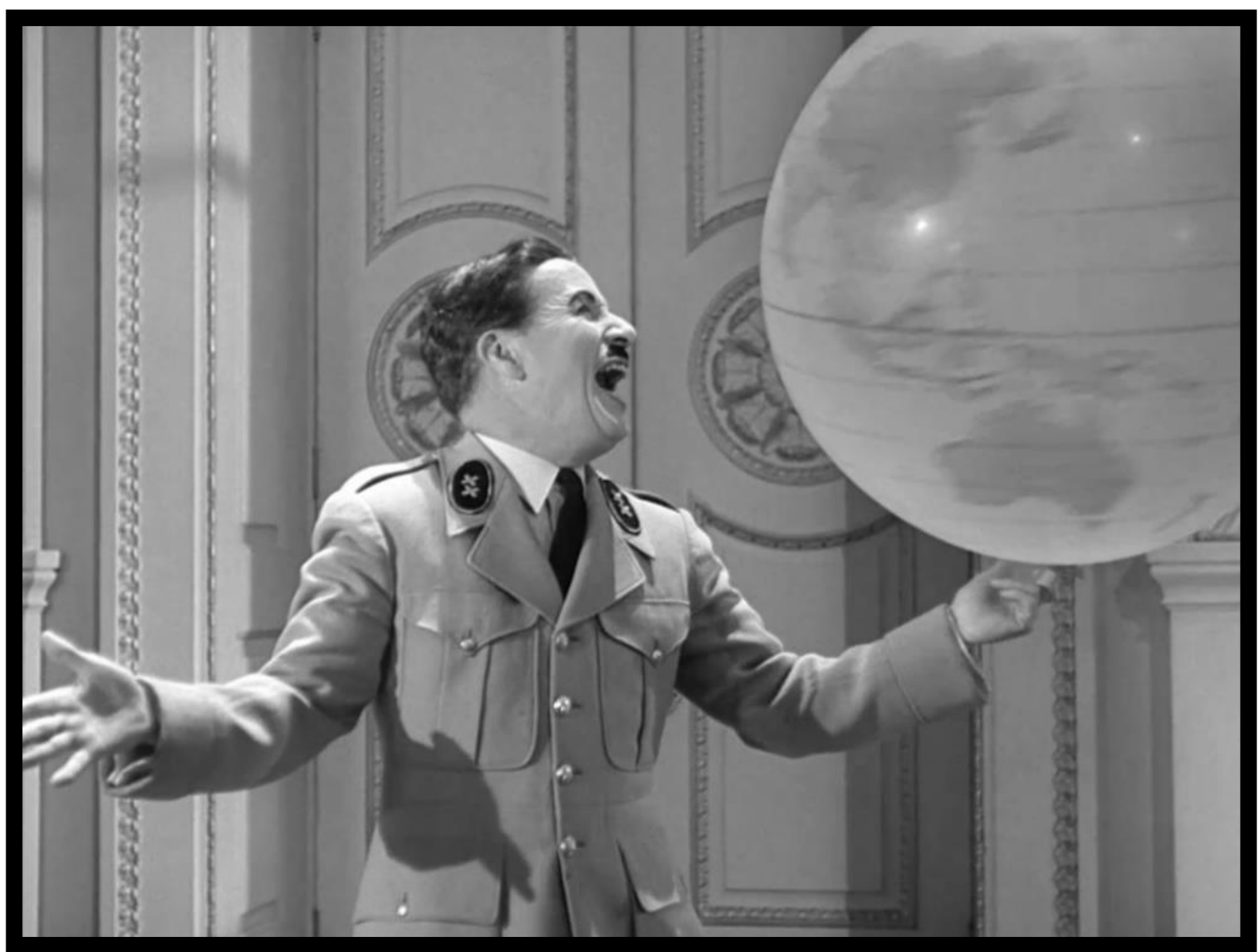

FIGURA 2 - THE GREAT DICTATOR - 1940 - ChARLES ChAPLIN

Apesar da ênfase na recepção individual da imagem da leitura aqui apresentada, uma vez que o espectador é tomado individualmente, não podemos nos esquecer que a coletividade é elemento fundamental na concepção de Benjamin sobre o cinema. A distração "esclarecida" possuiria a capacidade de fazer emergir toda uma potência revolucionária coletiva latente no grupo de espectadores daquela mídia nascente. Benjamin se mostra intrigado com os movimentos de autorregulação que se manifestam na sessão de cinema. Ele afirma:

O comportamento progressista se caracteriza pela ligação direta e interna entre o prazer de ver e sentir, por um lado, e a atitude do especialista, por outro. Esse vínculo constitui um valioso indício social. Quanto mais se reduz a significação social de uma arte, maior fica a distância, no público, entre a atitude de fruição e a atitude crítica, como se evidencia com o exemplo da pintura. Desfruta-se o que é

conhecimento rotinizado, configurava o embrião materialista de um novo lluminismo que finalmente desagua na conformação de uma ordem social superior". ARANTES, Otília. Os Novos Museus. Novos Estudos CEBRAP. № 31. Outubro, 1991. pp. 161-169. P. 163.

Mestre em Filosofia pela Universidade Estadual do Ceará. Brasileiro, residente em FortalezaCE. Email: mateusgoncalves@gmail.com 
convencional, sem criticá-lo; critica-se o que é novo, sem desfrutá-lo. Não é assim no cinema. O decisivo, aqui, é que no cinema, mais que em qualquer outra arte, as reações do indivíduo, cuja soma constitui a reação coletiva do público, são condicionadas, desde o início, pelo caráter coletivo dessa reação. Ao mesmo tempo que essas reações se manifestam, elas se controlam mutuamente. De novo, a comparação com a pintura se revela útil. Os pintores queriam que seus quadros fossem vistos por uma pessoa, ou poucas. A contemplação simultânea de quadros por um grande público, que se iniciou no século XIX, é um sintoma precoce da crise da pintura, que não foi determinada apenas pelo advento da fotografia, mas independentemente dela, através do apelo dirigido às massas pela obra de arte. (BENJAMIN, 1985, 187-188)

A recepção coletiva do cinema de fato inaugura uma nova maneira de lidar com a arte. Além de depender da coletividade, o cinema é capaz de organizar esse coletivo espacial e temporalmente. Seu espaço é construído para o uso de pequenas multidões e de forma alguma é como o espaço de observação de uma pintura num museu, que comportaria poucos espectadores por vez. Uma vez distribuídos na sala de projeção o conjunto de espectadores formado agora em público se organiza durante o tempo de exibição do filme autorregulando suas reações. O riso, o espanto, o choro são reações que se regulam no microcosmo social da sala de cinema. Naquele ambiente cria-se um ritmo regido pela narrativa fílmica e pela montagem das sequências ${ }^{5}$.

A simultaneidade entre desfrute e criticidade que era improvável na pintura se torna possível na recepção coletiva de um filme. A reprodutibilidade técnica ocasiona uma transformação no modo de percepção da obra de arte, o que a conduz a lançar seu apelo a uma recepção massificada. Na recepção coletiva se encontra o potencial revolucionário da massa e o despertar para a consciência de seu poder que começa no controle do ator.

Portanto, se as reações dos espectadores se condicionam entre si, se controlam e reagem em conjunto, na possibilidade dessa reação coletiva autogerida talvez esteja a centelha de um poder social. Benjamin sempre retorna à pintura como contraponto do cinema. No caso da pintura, um meio artístico

\footnotetext{
5 É difícil pensar como se poderia aproveitar essa mobilização social para fins de emancipação do homem. Benjamin não deixa claro como se daria essa possibilidade e a leitura do texto termina por deixar mais perguntas do que respostas. De qualquer forma, é interessante pensar no que significaria dizer que pela primeira vez na história da arte seria possível evitar o axioma do "desfruta-se o que é convencional, sem criticá-lo; critica-se o que é novo, sem desfrutá-lo". 0 que instiga Benjamin é a possibilidade do cinema de unir desfrute e atitude crítica.
}

Mestre em Filosofia pela Universidade Estadual do Ceará. Brasileiro, residente em FortalezaCE. Email: mateusgoncalves@gmail.com 
que surgiu com o objetivo de ser contemplado por poucas pessoas, o público não é capaz de se controlar.

Por mais que se tentasse confrontar a pintura com a massa do público, nas galerias e salões, esse público não podia de modo algum, na recepção das obras, organizar-se e controlar-se. Teria que recorrer ao escândalo. Assim, o mesmo público, que tem uma reação progressista diante de um filme burlesco, tem uma reação retrógrada diante do surrealismo ${ }^{6}$. (BENJAMIN, 1985, 188)

Defronte a uma obra vanguardista como a do surrealismo, um espectador que na sessão de cinema compreendera criticamente uma cena burlesca, pode ser incapaz de desempenhar uma atitude crítica por meio do recolhimento necessário para tal. Distraidamente gera uma compreensão crítica, mas, na contemplação de um quadro vanguardista, descarta-o tal qual um desenho malacabado e incompreensível.

Um outro aspecto que costuma ser compreendido sob o ponto de vista da alienação e do escapismo também se apresenta em Benjamin como uma possibilidade emancipatória. $\mathrm{O}$ autor se refere a essa questão sob o nome de vingança onírica. Afirma o autor:

Porque é diante de um aparelho que a esmagadora maioria dos citadinos precisa alienar-se de sua humanidade, nos balcões e nas fábricas, durante o dia de trabalho. À noite, as mesmas massas enchem os cinemas para assistirem à vingança que o intérprete executa em nome delas, na medida em que o ator não somente afirma diante do aparelho sua humanidade (ou o que aparece como tal aos olhos dos espectadores), como coloca esse aparelho a serviço do seu próprio triunfo. (BENJAMIN, 1985, 179)

Secretamente o operário executa seu plano de vingança nas noites de cinema. A questão da catarse que envolve uma sessão de cinema pode ser vista como embotamento crítico ou possibilidade de emancipação. A primeira posição se remeteria ao cinema como um instrumento para aplacar a indignação à sua

\footnotetext{
${ }^{6} \mathrm{Na}$ edição em português há um problema de tradução que compromete a interpretação. $\mathrm{A}$ tradução de Rouanet fala em "filme surrealista". Ele escreve: "Assim, o mesmo público, que tem uma reação progressista diante de um filme burlesco, tem uma reação retrógrada diante de um filme surrealista”. No original está escrito: „Damit wird ebendasselbe Publikum, das vor dem Groteskfilm fortschrittlich reagiert, vor dem Surrealismus zu einern rückständigen“".
}

Original em alemão extraído de: BENJAMIN, Walter. Das Kunstwerk im Zeitalter seiner technischen Reproduzierbarkeit. In: Gesammelte Schriften. Vol. I. Frankfurt am Main: Suhrkamp Verlag, 1991, p. 460.

Mestre em Filosofia pela Universidade Estadual do Ceará. Brasileiro, residente em Fortaleza-

CE. Email: mateusgoncalves@gmail.com 
condição social, enfraquecendo a revolta da situação de classe do operariado que poderia se revelar transformador. $O$ segundo se trata de uma possibilidade para o despertar da atitude política. A tese do cinema como alienação acredita no primeiro, enquanto que Benjamin, evidentemente sem negar a primeira, parece se perguntar sobre as possibilidades de concretização do segundo. A satisfação que o público experimenta ao observar o ator executar a justiça na tela em projeção é comparável à satisfação de sua própria vingança contra a máquina que lhe expropria a humanidade no horário de trabalho. O cinema tornase o lugar em que a técnica compensa o espectador pela exploração diurna. Essa possibilidade nos leva à questão da retomada do equilíbrio entre homem e aparelho. Benjamin afirma:

\begin{abstract}
Uma das funções sociais mais importantes do cinema é criar um equilíbrio entre o homem e o aparelho. O cinema não realiza essa tarefa apenas pelo modo com que o homem se representa diante do aparelho, mas pelo modo com que ele representa o mundo graças a esse aparelho, Através dos seus grandes planos, de sua ênfase sobre pormenores ocultos dos objetos que nos são familiares, e de sua investigação dos ambientes mais vulgares sob a direção genial da objetiva, o cinema faz-nos vislumbrar, por um lado, os mil condicionamentos que determinaram nossa existência, e por outro assegura-nos um grande e insuspeitado espaço de liberdade. (BENJAMIN, 1985, 189)
\end{abstract}

A reconciliação entre homem e técnica se revela pelo significado político que o cinema manifesta. A tarefa de criar tal equilíbrio não se dá apenas por meio do modo como o ator é absorvido pela câmera no momento em que representa, mas também está presente na imensa possibilidade de descoberta da realidade trazida tanto pela inserção nos pormenores da matéria quanto na ampliação do todo da visão. Com o cinema é possível vislumbrar os condicionamentos de nossa existência, ao mesmo tempo que nos garante um grande espaço de liberdade. Este é adquirido pelos cortes e distâncias percorridas que desafiam a construção cronológica e contígua do espaço-tempo; aquele por permitir o debruçar-se sobre o que ocasiona nossa existência, pela oportunidade de nos descobrirmos como uma engrenagem ao percorrermos juntamente com Chaplin o interior de um gigante aparelho mecânico. O cinema abre o caminho que leva à descoberta do inconsciente óptico, um mundo novo 
da percepção que se revela pela técnica. Se o slow-motion, a tele-objetiva e a macro fotografia aprimoraram a percepção humana a ponto de nos ajudar a compreender a estrutura constitutiva da realidade física, o cinema nos oferece mais um caminho para a compreensão crítica da estrutura social.

O inconsciente óptico possui uma forte ligação com o inconsciente pulsional. A imagem cinematográfica preenche 0 imaginário do público intrometendo-se mesmo em seus sonhos e pesadelos. "O cinema introduziu uma brecha na verdade de Heráclito segundo a qual o mundo dos homens acordados é comum, o dos que dormem é privado" (BENJAMIN, 1985, 190). Por esse ângulo, o potencial de mobilização política das massas pelo filme atinge um nível inimaginável anteriormente. Hoje é possível sonhar coletivamente?

A abertura do mundo inconsciente da visão pelo cinema cria novos espaços de liberdade. Um desses espaços é ocupado pela possibilidade da explosão terapêutica do inconsciente. O mesmo processo de tecnização que acelera o processo de desumanização do homem que se aliena de si mesmo na cadeia de produção industrial apresenta com o cinema a possibilidade da imunização contra as psicoses de massa provenientes desse processo. Tratase do cinema como explosão terapêutica do inconsciente:

\begin{abstract}
Se levarmos em conta as perigosas tensões que a tecnização, com todas as suas consequências, engendrou nas massas - tensões que em estágios críticos assumem um caráter psicótico -, perceberemos que essa mesma tecnização abriu a possibilidade de uma imunização contra tais psicoses de massa através de certos filmes, capazes de impedir, pelo desenvolvimento artificial de fantasias sadomasoquistas, seu amadurecimento natural e perigoso. A hilaridade coletiva representa a eclosão precoce e saudável dessa psicose de massa. A enorme quantidade de episódios grotescos atualmente consumidos no cinema constitui um índice impressionante dos perigos que ameaçam a humanidade, resultantes das repressões que a civilização traz consigo. Os filmes grotescos, dos Estados Unidos, e os filmes de Disney, produzem uma explosão terapêutica do inconsciente. Seu precursor foi o excêntrico. Nos novos espaços de liberdade abertos pelo filme, ele foi o primeiro a sentir-se em casa. É aqui que se situa Chaplin, como figura histórica. (BENJAMIN, 1985, 190)
\end{abstract}

\footnotetext{
${ }^{7}$ Lembra ainda a fala de Joseph Campbell em sua célebre entrevista a Bill Moyers transcrita em livro: O mito é o sonho público. O sonho é o mito privado.
}

Mestre em Filosofia pela Universidade Estadual do Ceará. Brasileiro, residente em FortalezaCE. Email: mateusgoncalves@gmail.com 
A relação entre inconsciente óptico e inconsciente pulsional se reafirma na medida em que o cinema possibilita o alívio das tensões reprimidas pela civilização. A energia pulsional é suavizada na explosão terapêutica a que o filme pode conduzir. O caráter excêntrico que, segundo Benjamin, foi o precursor dessa explosão é uma canalização da energia gerada pelas psicoses de massa. $\mathrm{Na}$ excentricidade busca-se lidar com questões psíquicas não resolvidas com base em um comportamento incomum. Chaplin representa, nesse sentido, tanto o personagem que se comporta de forma excêntrica quanto o filme que oferece o alívio das tensões com base na narração da experiência do outro na tela. À possibilidade de mobilizar a massa pelo cinema soma-se os seus efeitos terapêuticos contra as doenças psíquicas da técnica.

\section{REFERÊNCIAS}

ARANTES, Otilia. "Os Novos Museus" in:_Novos Estudos CEBRAP, N. 31, Outubro, 1991, pp 161-169.

BENJAMIN, Walter. "A obra de arte na era de sua reprodutibilidade técnica" in: Magia e Técnica, Arte e Política - ensaios sobre literatura e história da cultura (tradução de Sérgio Paulo Rouanet), São Paulo: Brasiliense, 1985.

Charles Baudelaire: um lírico no auge do capitalismo Obras Escolhidas IIII, Tradução de José Carlos Martins Barbosa e Hemerson Alves Baptista, São Paulo: Brasiliense, 1989.

Origem do drama barroco alemão, Tradução de Sérgio Paulo Rouanet, São Paulo: Brasiliense, 1984.

CALLADO, "O drama da alegoria no século XVII barroco" in: Kalagatos: Revista do Mestrado de Filosofia, V. I, N.2, Fortaleza: Eduece, 2004.

COUSINS, Mark, The Story of Film, London: Pavilion Books, 2004. 
DANTO, Arthur. "The Artworld" in:_The Journal of Philosophy. Vol.61. Issue 19 American Philosophical Association, Eastern Division Sixty-First Annual Meeting (Oct.15,1964) pp571-594.

DUARTE, Rodrigo (Org.) O Belo Autônomo: Textos clássicos de estética, Belo Horizonte: Autêntica, 2013.

GOMBRICH, Ernst. A História da Arte. Tradução de Cristina de Assis Serra. LTC, Rio de Janeiro, 2013. 